\title{
Local Anesthetic Use for Pain Relief Following Laparoscopic Ventral Hernia Repair: A Systematic Review
}

\author{
Vaaiga Autagavaia ${ }^{1}$, Jamie-Lee Rahiri ${ }^{2}$, Melanie Lauti ${ }^{3}$, Lydia Poole ${ }^{4}$, Garth Poole ${ }^{5}$, Andrew G Hill ${ }^{6}$
}

\begin{abstract}
Aim: To assess the effectiveness of the addition of local anesthetic (LA) techniques in reducing pain and morphine consumption in the first 24 hours following laparoscopic ventral hernia repair (LVHR) in adults.

Background: Ventral hernias (VH) are a common condition; with risk factors (including obesity), the incidence of VH is projected to increase. Surgical VH repair is required for symptom relief and to prevent related complications. LVHR has significant advantages over open repair, with reduced infectious complications, shorter hospital stays, and more favorable outcomes in obese patients. However, in comparisonto open repair LVHR patients often experience severe pain post-LVHR. LA is an important part of multimodal analgesia regimes and their use in the context of post-operative LVHR pain management is growing in importance.

Review results: A systematic review was performed according to PRISMA using search terms related to LA, LVHR post-operative pain, and morphine consumption; studies were limited to adults ( $>18$ years) and randomized control trials (RCT). Four RCT met the inclusion criteria. All studies compared bupivacaine with normal saline, one also used bupivacaine with epinephrine; varying LA interventions were used. One study showed a statistically significant, but small $(0.08 \mathrm{mg})$ reduction in pain scores at 24 hours, which is likely to be clinically insignificant. Three studies showed an overall reduction in morphine consumption at 24 hours, with only one reaching statistical and clinical significance.

Conclusion: Bupivicaine LA interventions post-LVHR did not reduce pain scores at 24 hours, but morphine consumption appeared to have been reduced.

Clinical significance: Despite some evidence of reduction in morphine consumption in the first 24 hours post-LVHR, further investigation is required regarding post-operative LVHR pain management using LA, including agent and mode of delivery.

Keywords: Analgesia, Laparoscopy, Outcomes, Ventral hernia.

World Journal of Laparoscopic Surgery (2019): 10.5005/jp-journals-10033-1349
\end{abstract}

\section{BACKGROUND}

A ventral hernia $(\mathrm{VH})$ is a fascial defect in the anterior abdominal wall. Primary VH includes epigastric, umbilical, and spigelian hernias. A secondary defect, or incisional hernia, is one that develops at a previous surgical incision site. ${ }^{1} \mathrm{VH}$ are a common condition and risk factors include obesity, previous abdominal surgery, and chronic elevated intra-abdominal pressure. ${ }^{2}$ With the current obesity epidemic, the incidence of $\mathrm{VH}$ formation is projected to increase. ${ }^{3,4}$ Consequently, the optimization of postoperative care following $\mathrm{VH}$ repair is critical to the effective management of this increasingly significant issue.

VH require surgical repair to relieve symptoms and prevent complications, such as uncontrolled pain and hernia strangulation. ${ }^{5,6}$ Open mesh repair has been the gold standard since it has been provedto be superior to open suture repair owing to significantly lower recurrence rates. ${ }^{7}$ However, LVHR has grown in popularity since its introduction in $1993 .{ }^{8}$ Multiple studies have demonstrated a number of advantages of LVHR over open repair, including decreased infectious complications and shorter hospital admissions. ${ }^{9-12}$ Furthermore, LVHR appears to be favorable in obese patients owing to lower complication rates. ${ }^{13-16}$

Laparoscopic surgery has long been considered less painful in comparison with open surgery, yet trials have reported no difference in acute or chronic pain between open and LVHR. ${ }^{17-19}$ In fact, patients often experience severe pain following LVHR and this remains a significant clinical problem. It is hypothesized that this severe pain is attributable to techniques of mesh fixation during ventral herniorrhaphy. ${ }^{20-22}$ Mesh may be secured with sutures or tacks, which pass through the peritoneum, fascia, and muscle of the anterior abdominal wall. Both techniques are associated with
${ }^{1-6}$ Department of Surgery, South Auckland Clinical Campus, The University of Auckland, Auckland, New Zealand

Corresponding Author: Vaaiga Autagavaia, Department of Surgery, South Auckland Clinical Campus, The University of Auckland, Auckland, New Zealand, Phone: +64 92760000, e-mail: v.autagavaia@ auckland.ac.nz

How to cite this article: Autagavaia V, Rahiri J-L, Lauti M, et al. Local Anesthetic Use for Pain Relief Following Laparoscopic Ventral Hernia Repair: A Systematic Review. World J Lap Surg 2019;12(1):33-38.

Source of support:The University of Auckland, Auckland, New Zealand Conflict of interest: None

significant abdominal wall pain impacting on short- and long-term patient wellbeing, recovery, and satisfaction. ${ }^{23}$

Local anesthesia has become an important addition to multimodal analgesia regimens for postoperative pain. Local anesthesia prevents afferent nociceptive nerve transmission from the surgical site to the spinal cord, reducing the local inflammatory response and pain perception. This is clinically achieved by neuraxial blockade with epidural anesthesia, wound instillation, or compartment blocks. ${ }^{24}$ The objective of this systematic review was to assess the effectiveness of the addition of LA techniques in reducing pain and morphine consumption in the first 24 hours following LVHR in adults.

\section{Methods}

A systematic review was performed in accordance with the preferred reporting items for systematic reviews and meta-analyses (PRISMA) 
statement where possible. ${ }^{25}$ Two authors (JR and VA) independently performed electronic searches of four databases (MEDLINE, EMBASE, Cochrane Central Register of Controlled Trials, and Google Scholar). With the assistance of a subject librarian, the first author (JR) collated a list of keywords and search terms to incorporate them into the strategies adapted for each database. The search terms combined the concepts of LA, LVHR, post-operative pain, and morphine consumption (Table 1). Results were limited to adults ( $>18$ years) and randomized controlled trials (RCT). No other limitations were applied. Search results were downloaded and managed with RefWorks citation management software (ProQuest LLC, USA).

\section{Study Selection}

Abstracts were screened and full-text papers obtained to identify primary research studies reporting the effectiveness of the addition of LA techniques in reducing pain scores and morphine consumption in the first 24 hours following LVHR. All published studies comparing LA modalities for post-operative pain relief following LVHR by randomized trial were included. The primary outcomes of interest were pain scores at rest and total morphine consumption in the first 24 hours following LVHR. Exclusion criteria included nonrandomized studies, pediatric studies, and those articles for which full-text publications were not available (e.g., conference abstracts). Three reviewers (JR, LP, and VA) independently performed the searches and examined titles and abstracts to exclude irrelevant reports and produce a list of studies for full-text review in an iterative process. Any disagreement over inclusion or exclusion was discussed with the senior author (AGH) and a consensus reached. Additional articles and abstracts were retrieved by manually examining reference lists of relevant publications. The last search was performed on June 19, 2018.

\section{Data Extraction}

Data extraction for morphine consumption and pain scores in the first 24 hours was performed independently by two reviewers (JR and VA) and entered into predesigned electronic tables. Data were reported as mean \pm standard deviation (SD) where possible. Morphine consumption within the first 24 hours following surgery was reported as morphine equivalents where possible and as reported by individual trials. The median score was used as an estimate of the mean where the latter was not reported.

Table 1: Search strategy used in OVID Medline ${ }^{\circledast}$ in-process and other non-indexed citations (search strategy was modified as required for each database used. exp. exploded MeSH term, mp key word, $\mathrm{mt}$ methods)

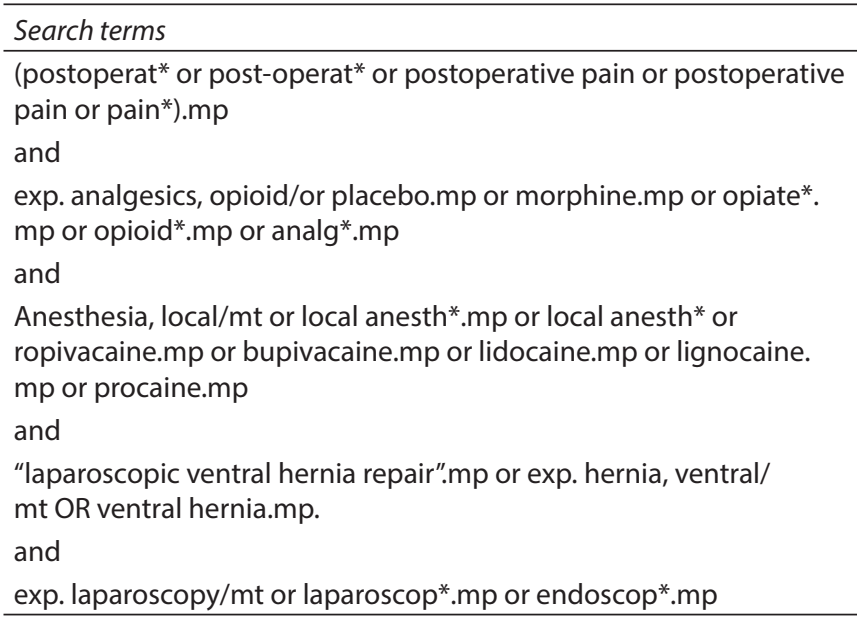

SD measures were attempted based on the methods described in the Cochrane Handbook of Systematic Reviews of Interventions, where attempts to contact authors for clarification were unsuccessful (up to two emails). ${ }^{26}$

\section{Risk of Bias Assessment}

The Cochrane Collaboration tool for assessing risk of bias was implemented and generated by RevMan 5.1.27 Two reviewers (JR and LP) independently assessed the methodological quality of trials for sequence generation, allocation concealment, blinding of participants and personnel, blinding of outcome assessment, incomplete outcome data, selective reporting, lost to follow-up, intention-to-treat, and financial conflicts. ${ }^{28}$

\section{Review Results}

The literature search identified 637 records in the initial database search. A PRISMA flow diagram for the systematic review is presented in Flowchart 1. Four RCT met the inclusion criteria and were included in the review. ${ }^{29-32}$ All four studies compared bupivacaine with normal saline and only one of these studies used bupivacaine with epinephrine (Table 2). All studies were classified as having a low risk of bias (Fig. 1). Variations in the timing of outcome measures, the duration and type of the intervention and the study cohorts limited meaningful synthesis of the data. The data are therefore presented as a narrative review.

\section{Pain Scores}

There was variation in the types of post-operative pain-scoring questionnaires used in the included studies. Two studies utilized visual analog scores (VAS), ${ }^{29,30}$ one study used a numerical rating scale (NRS), ${ }^{31}$ and the remaining study used VAS and present pain intensity (PPI) scores. ${ }^{32}$ Only one trial, the largest of the included studies, demonstrated a statistically significant difference in pain scores at 24 hours. ${ }^{30}$ This trial was assessed as having a low risk of bias and bupivacaine was compared with saline using a laparoscopic transverse abdominis plane (TAP) block and only a very small difference $(0.08 \mathrm{mg})$ was noted in pain scores, which is unlikely to be clinically significant. However, a statistically and clinically significant difference in morphine consumption clearly favored the TAP block with bupivacaine (see below). Three trials showed a significant reduction in the reported pain scores at the one-hour mark, of which two reached statistical significance in favor of the intervention group at one hour post-surgery. ${ }^{29-31}$

\section{Morphine Consumption}

Three of the four included studies demonstrated decreased morphine consumption in the intervention group at 24 hours, of which only one reached statistical and clinical significance. ${ }^{30}$ The remaining study reported a statistically insignificant increase in morphine use in the intervention group at 24 hours following LVHR and did not provide a measure of variance. ${ }^{32}$

\section{Complications and Adverse Effects}

There were no reports of adverse events following the application of LA interventions. None of the trials reported plasma levels of LA agents. Only one study reported a major complication: a single case of mesh infection with methicillin-resistant Staphylococcus aureus. ${ }^{32}$

\section{Discussion}

This systematic review includes four trials comparing various bupivacaine interventions to usual/standard care or a saline control 
Flowchart 1: PRISMA flow diagram of study selection

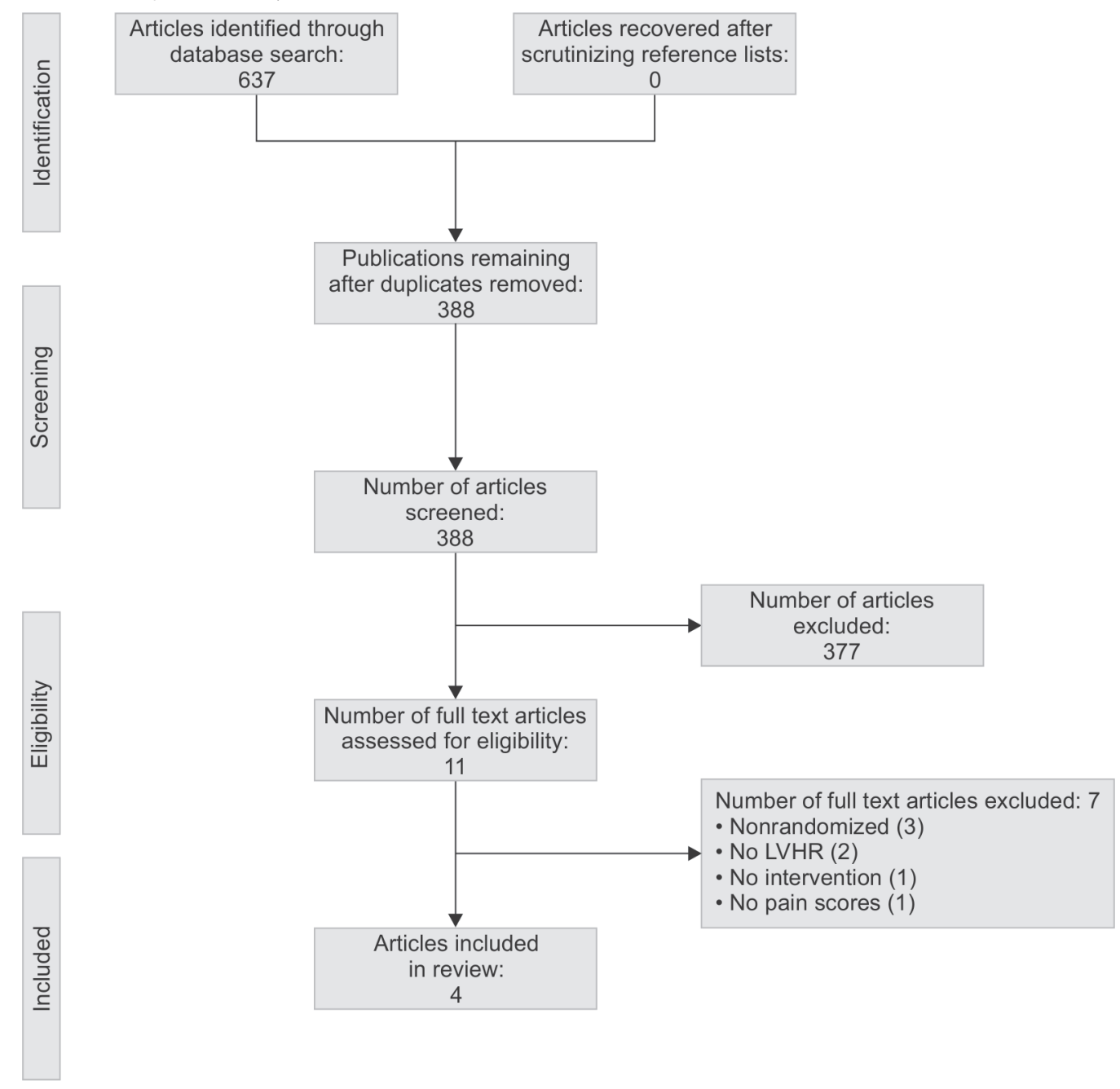

for improving postoperative pain and morphine consumption following LVHR. ${ }^{29-32}$ These interventions included peripheral nerve blockade, continuous intraperitoneal LA infusion, and single-shot intraperitoneal LA instillation techniques. Although the use of bupivacaine did not seem to significantly improve pain score measures, it did seem to reduce morphine consumption at 24 hours.

Although all included trials compared different interventions, bupivacaine was consistently the chosen LA agent. Bupivacaine is a long-acting LA agent that is easily used with minimal side effects. ${ }^{33}$ Among other factors, the analgesic efficacy of bupivacaine depends on the method of delivery and the desired effect site. In addition, it has a rapid onset of action and, depending on dosage and concentration, an elimination half-life ranging from 1.5 to 8 hours. ${ }^{34-36}$ Interestingly, the single trial that used bupivacaine with epinephrine did not show a prolonged analgesic effect as would be expected. Given these pharmacokinetic properties, it is unsurprising that patients experienced less pain in the early postoperative phase within the three trials that compared singleinjection LA analgesic interventions. ${ }^{29-31}$ These findings suggest that single-bolus LA analgesic interventions with bupivacaine may be limited principally by the short duration of the analgesic agent.

Previous studies have shown successful prolongation of LA analgesic effects with continuous LA infusions via perineural catheters and mechanical pain pump devices. ${ }^{37,38}$ Despite this,
Rosen et al. were unable to demonstrate a difference in postoperative pain scores and morphine consumption following LVHR, using this technique. ${ }^{32} \mathrm{~A}$ possible reason for the negative findings in this trial may lie with the technical aspects of catheter placement. With the successful implementation of LA infusions in other procedures, the development of this technique should be explored further with attention to the insertion technique and LA effect site.

The administration of LA agents to wound sites improves pain and morphine use after laparoscopic surgery owing to ease of application, effective afferent nociceptive blockade, and reduction in the local inflammatory response. ${ }^{39-41}$ While opioid analgesics are the mainstay of postoperative analgesia following LVHR and cannot be eliminated from multimodal regimens of analgesia, there are many unwanted adverse effects associated with their use which can hinder recovery. ${ }^{42}$ Despite no significant difference in pain scores in the included trials, an overall reduction in total morphine consumption was observed in the intervention group in three of the trials. ${ }^{29-31}$ While there are multiple factors at play during postoperative recovery, an observation between all interventions compared was that patients were less likely to ask for additional analgesia in the early post-operative phase following LA application. Bellows and colleagues noticed that patients requested the majority of pain relief in the first four hours post-surgery in the control group. ${ }^{29}$ The opposite was seen in the intervention group. 
Table 2: Study characteristics of included trials comparing LA interventions for postoperative pain up to 24 hours following LVHR

\begin{tabular}{|c|c|c|c|c|c|c|c|}
\hline Study & $\begin{array}{l}\text { Design, } \\
N \text { [intervention/ } \\
\text { control] }\end{array}$ & Intervention & LA agent, control & $\begin{array}{l}\text { Mean morphine } \\
\text { consumption in } \\
24 \text { hours }(\mathrm{mg}) \\
\text { [intervention/ } \\
\text { control] }\end{array}$ & $\begin{array}{l}\text { Pain score } \\
\text { measure } \\
(0-10)^{+}\end{array}$ & $\begin{array}{l}\text { Mean pain scores at } \\
\text { rest [intervention/ } \\
\text { control] }\end{array}$ & $\begin{array}{l}\text { Main findings } \\
\text { of intervention }\end{array}$ \\
\hline Bellows ${ }^{29}$ & $\mathrm{RCT}, 9 / 9$ & $\begin{array}{l}\text { Trans-abdominal LA } \\
\text { injected at suture } \\
\text { sites prior to suture } \\
\text { placement }\end{array}$ & $\begin{array}{l}10 \mathrm{~mL} 0.25 \% \\
\text { bupivacaine with } \\
\text { epinephrine, no } \\
\text { control }\end{array}$ & $\begin{array}{l}24.1 \pm 7.2 / \\
26.3 \pm 9.2\end{array}$ & VAS & $\begin{array}{l}1 \text { hours: } 2.2 \pm 0.8 / \\
6.4 \pm 0.9^{*} \\
2 \text { hours: } 3.1 \pm 0.9 / \\
3.9 \pm 1.1 \\
4 \text { hours: } 1.1 \pm 0.4 / \\
2.6 \pm 0.9 \\
24 \text { hours: } 2.3 \pm \\
0.8 / 2.3 \pm 1.0\end{array}$ & $\begin{array}{l}\text { Significant } \\
\text { reduction in } \\
\text { pain scores at } \\
\text { one hour after } \\
\text { surgery }\end{array}$ \\
\hline Fields $s^{30}$ & $\mathrm{RCT}, 52 / 48$ & $\begin{array}{l}\text { Laparoscopic assisted } \\
\text { TAP block }\end{array}$ & $\begin{array}{l}50-60 \mathrm{~mL} 0.25 \% \\
\text { bupivacaine, } 0.9 \% \\
\text { normal saline }\end{array}$ & $25.64 / 42.56^{*}$ & VAS & $\begin{array}{l}1 \text { hours: } 5.19 \pm 0.39 / \\
6.46 \pm 0.38^{*} \\
24 \text { hours: } 4.60 \pm \\
0.39 / 4.52 \pm 0.31^{*}\end{array}$ & $\begin{array}{l}\text { Significant } \\
\text { reduction in } \\
\text { pain scores and } \\
\text { total morphine } \\
\text { consumption in } \\
24 \text { hours }\end{array}$ \\
\hline Gough $^{31}$ & $\mathrm{RCT}, 42 / 38$ & $\begin{array}{l}\text { Peri-prosthetic LA } \\
\text { injection, with all } \\
\text { patients receiving LA } \\
\text { port site injections }\end{array}$ & $\begin{array}{l}0.5 \% \text { bupivacaine, } \\
0.9 \% \text { normal } \\
\text { saline }\end{array}$ & $\begin{array}{l}4.8 \pm 17.3 / \\
6.7 \pm 15.4\end{array}$ & NRS & $\begin{array}{l}<1.5 \text { hours: } 4.4 \pm 2.4 / \\
4.8 \pm 2.2 \\
22.5-24.5 \text { hours: } \\
3.6 \pm 2.5 / 2.7 \pm 1.4\end{array}$ & $\begin{array}{l}\text { Reduced pain } \\
\text { scores and total } \\
\text { morphine con- } \\
\text { sumption (not } \\
\text { significant) }\end{array}$ \\
\hline Rosen $^{32}$ & $\mathrm{RCT}, 37 / 36$ & $\begin{array}{l}\text { Continuous } \\
\text { elastomeric pain } \\
\text { pump infusion of LA } \\
\text { for } 48 \text { hours above } \\
\text { the mesh in the } \\
\text { hernia sac }\end{array}$ & $\begin{array}{l}0.5 \% \text { bupivacaine, } \\
0.9 \% \text { normal } \\
\text { saline }\end{array}$ & $52.2 / 44.5$ & VAS & $\begin{array}{l}0: 1.7 / 2.3 \\
8 \text { hours: } 5.7 / 5.5 \\
16 \text { hours: } 5.4 / 5.6 \\
24 \text { hours: } 5.0 / 6.0\end{array}$ & $\begin{array}{l}\text { No advantage } \\
\text { in reduction } \\
\text { pain scores and } \\
\text { total morphine } \\
\text { consumption in } \\
24 \text { hours }\end{array}$ \\
\hline
\end{tabular}

VAS, visual analog scale; LA, local anesthetic; LVHR, laparoscopic ventral hernia repair; TAP, transverse abdominis plane; NRS, numerical rating scale; VRS, verbal rating score; $\mathrm{PPI}$, present pain intensity; $\mathrm{RCT}$, randomized controlled trial.

${ }^{\dagger}$ All pain scores use a $0-10$ point scale with a score of 10 signifying the worst possible pain.

${ }^{*} p<0.05$.

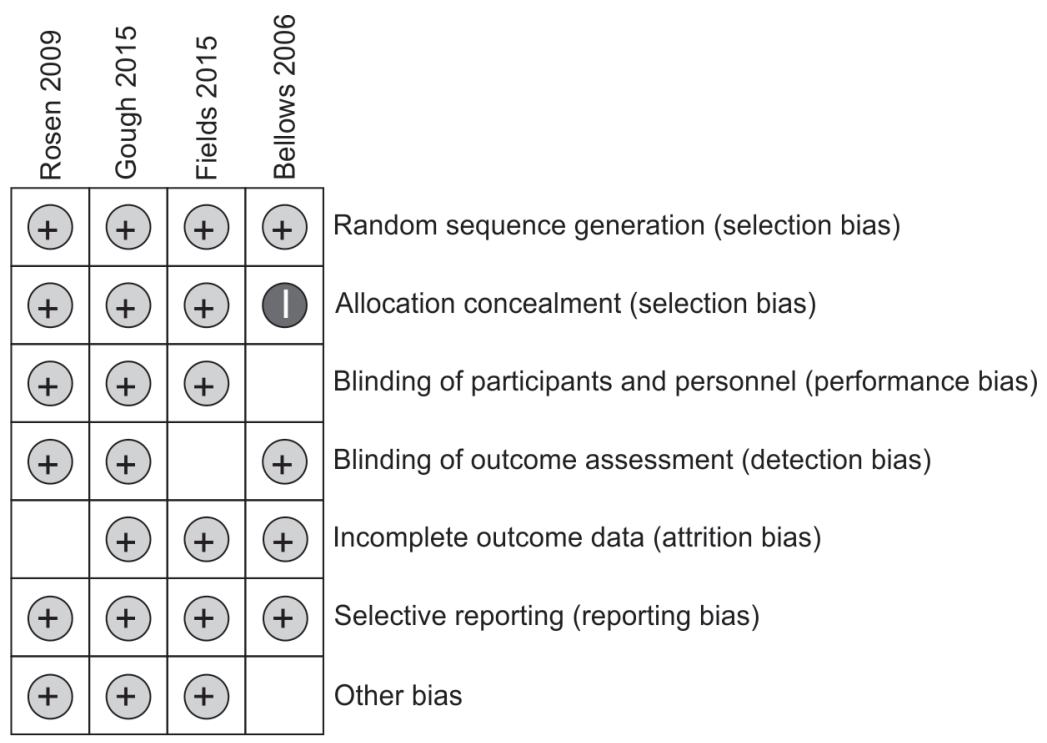

Fig. 1: Cochrane risk of bias figure 
This particular study demonstrates that the early postoperative phase serves as the best time for single-shot LA interventions to be effective.

\section{LiMITATIONS}

The present review was limited by the lack of available trials. All included studies were heterogeneous comparing different interventions; hence, no quantitative analysis or meta-analysis was possible.

\section{ConcLusion}

While bupivacaine interventions did not improve early postoperative pain scores, they appeared to reduce the amount of morphine consumed in the first 24 hours following LVHR. Further definitive conclusions cannot be made owing to the limited and heterogeneous nature of the available evidence. The management of pain following LVHR would benefit from further good quality trials investigating LA agents and their mode of delivery.

\section{Clinical Significance}

Despite some evidence of reduction in morphine consumption in the first 24 hours post-LVHR, further investigation is required regarding postoperative LVHR pain management using LA, including agent and mode of delivery.

\section{ACKnOWLedgments}

The authors sincerely thank Anne Wilson, Subject Librarian from the Counties Manukau Health Library for assistance with the search strategies. Dr Jamie-Lee Rahiri is a recipient of a Health Research Council of New Zealand Māori PhD Scholarship.

\section{References}

1. Muysoms FE, Miserez M, et al. Classification of primary and incisional abdominal wall hernias. Hernia 2009;13(4):407-414. DOI: 10.1007/ s10029-009-0518-x.

2. Moreno-Egea A, Carrillo-Alcaraz A. Management of non-midline incisional hernia by the laparoscopic approach: results of a long-term follow-up prospective study. Surg Endosc 2012;26:1069-1073. DOI: 10.1007/s00464-011-2001-x.

3. Weerasekera D, Cox S, et al. Annual update of key results: New Zealand health survey. Wellington: Ministry of Health; 2015.

4. Poulose BK, Shelton J, et al. Epidemiology and cost of ventral hernia repair: making the case for hernia research. Hernia 2012;16(2):179-183. DOI: 10.1007/s10029-011-0879-9.

5. Melvin WS, Renton D. Laparoscopic ventral hernia repair. World J Surg 2011;35:1496-1499.

6. Evans KK, Chim H, et al. Survey on ventral hernias: surgeon indications, contraindications, and management of large ventral hernias. Am J Surg 2012;78(4):388-397.

7. Burger JW, Luijendijk RW, et al. Long-term follow-up of a randomized controlled trial of suture vs mesh repair of incisional hernia. Ann Surg 2004;240:578-583. DOI: 10.1007/s10029-015-1345-x.

8. LeBlanc KA, Booth WV. Laparoscopic repair of incisional abdominal hernias using expanded polytetrafluoroethylene: preliminary findings. Surg Laparosc Endosc 1993;3:39-41.

9. Forbes SS, Eskicioglu C, et al. Meta-analysis of randomized controlled trials comparing open and laparoscopic ventral and incisional hernia repair with mesh. Br J Surg 2009;96:851-858. DOI: 10.1002/ bjs.6668.

10. Sajid MS, Bokhari SA, et al. Laparoscopic vs open repair of incisional/ ventral hernia: a meta-analysis. Am J Surg 2009;197:64-72. DOI: 10.1016/j.amjsurg.2007.12.051.
11. Kapischke M, Schulz T, et al. Open vs laparoscopic incisional hernia repair: something different from a meta-analysis. Surg Endosc 2008;22:2251-2260. DOI: 10.1007/s00464-008-9773-7.

12. Sauerland $S$, Walgenbach $M$, et al. Laparoscopic vs open surgical techniques for ventral or incisional hernia repair. Cochrane Database Syst Rev 2011 Mar 16(3):CD007781.DOI: 10.1002/14651858.CD007781. pub2.

13. Mavros MN, Athanasiou S, et al. Risk factors for mesh-related infections after hernia repair surgery: a meta-analysis of cohort studies. World J Surg 2011;35(11):2389-2398. DOI: 10.1007/s00268011-1266-5.

14. Shabanzadeh DM, Sorensen LT. Laparoscopic surgery compared with open surgery decreases surgical site infection in obese patients: a systematic review and meta-analysis. Ann Surg 2012;256(6):934-945. DOI: 10.1097/SLA.0b013e318269a46b.

15. Colon MJ, Kitamura R, et al. Laparoscopic umbilical hernia repair is the preferred approach in obese patients. Am J Surg 2013;205:231-236. DOI: 10.1016/j.amjsurg.2012.02.022.

16. Colavita PD, Tsirline VB, et al. Laparoscopic vs open hernia repair: outcomes and sociodemographic utilization results from the nationwide inpatient sample. Surg Endosc 2013;27(1):109-117. DOI: 10.1007/s00464-012-2432-z.

17. Misra MC, Bansal VK, et al. Comparison of laparoscopic and open repair of incisional and primary ventral hernia: results of a prospective randomized study. Surg Endosc 2006;20:1839-1845. DOI: 10.1007/ s00464-006-0118-0.

18. Barbaros U, Asoglu O, et al. The comparison of laparoscopic and open ventral hernia repairs: a prospective randomized study. Hernia 2007;11:51-56. DOI: 10.1007/s10029-006-0160-9.

19. Asencio F, Aguiló J, et al. Open randomized clinical trial of laparoscopic vs open incisional hernia repair. Surg Endosc 2009;23:1441-1448. DOI: 10.1007/s00464-008-0230-4.

20. Winslow ER, Diaz $S$, et al. Laparoscopic incisional hernia repair in a porcine model. What do transfixion sutures add? Surg Endosc 2004;18:529-535. DOI: 10.1007/s00464-003-8519-9.

21. Nguyen SQ, Divino CM, et al. Postoperative pain after laparoscopic ventral hernia repair: a prospective comparison of sutures vs tacks. JSLS 2008;12:113-116.

22. Wassenaar E, Schoenmaeckers E, et al. Meshfixation method and pain and quality of life after laparoscopic ventral or incisional hernia repair: a randomized trial of three fixation techniques. Surg Endosc 2010;24:1296-1302. DOI: 10.1007/s00464-009-0763-1.

23. Eriksen JR. Pain and convalescence following laparoscopic ventral hernia repair. Dan Med Bull 2011;58(12):B4369.

24. Holte K, Kehlet H. Epidural anaesthesia and analgesia: effects on surgical stress responses and implications for postoperative nutrition. Clin Nutr 2002;21:199-206.

25. Moher D, Shamseer $L$, et al. Preferred reporting items for systematic review and meta-analysis protocols (PRISMA-P) 2015 statement. Syst Rev 2015;4:1. DOI: 10.1186/2046-4053-4-1.

26. Higgins J, Green S. Cochrane Handbook for Systematic Review of Interventions. The Cochrane Collaboration. Version 5.1.0, 2011.

27. Higgins JP, Altman DG, et al. Cochrane Statistical Methods Group: The Cochrane Collaboration's tool for assessing risk of bias in randomised trials. BMJ 2011;343:5928. DOI: 10.1136/bmj.d5928.

28. Review Manager Version 5.3, Copenhagen: The Nordic Cochrane Centre, The Cochrane Collaboration, 2011.

29. Bellows C, Berger D. Infiltration of suture sites with local anesthesia for management of pain following laparoscopic ventral hernia repairs: a prospective randomised trial. JSLS 2006;10:345-350.

30. Fields AC, Gonzalez DO, et al. Laparoscopic-Assisted Transversus Abdominis Plane Block for Postoperative Pain Control in Laparoscopic Ventral Hernia Repair: A Randomized Controlled Trial. J Am Coll Surg 2015;21(2):462-469. DOI: 10.1016/j.jamcollsurg.2015.04.007.

31. Gough AE, Chang S, et al. Periprosthetic Anesthetic for Postoperative Pain After Laparoscopic Ventral Hernia Repair: A Randomized Clinical Trial. JAMA Surg 2015;150(9):835-840. DOI: 10.1001/ jamasurg.2015.1530. 
32. Rosen MJ, Duperier T, et al. Prospective randomized double-blind placebo-controlled trial of postoperative elastomeric pain pump devices used after laparoscopic ventral hernia repair. Surg Endosc 2009;23(12):2637-2643. DOI: 10.1007/s00464-009-0470-y.

33. Uskova A, O'Connor JE. Liposomal bupivacaine for regional anesthesia. Curr Opin Anaesthesiol 2015;28(5):593-597. DOI: 10.1097/ ACO.0000000000000240.

34. Morrison SG, Dominguez JJ, et al. A comparison of the electrocardiographic cardiotoxic effects of racemic bupivacaine, levobupivacaine, and ropivacaine in anesthetized swine. Anesth Analg 2000;90:1308-1314. DOI: 10.1097/00000539-200006000-00009.

35. Knudsen K, Beckman SM, et al. Central nervous and cardiovascular effects of i.v. infusions of ropivacaine, bupivacaine and placebo in volunteers. Br J Anaesth 1997;78(5):507-514. DOI: 10.1093/ bja/78.5.507.

36. McEvoy GK, Bethesda MD. American Hospital Formulary Service Drug Information Drug Information. American Society of Health System Pharmacists Inc; 2015.
37. Kahokehr A, Sammour T, et al. Intraperitoneal local anesthetic improves recovery after colon resection: a double-blinded randomized controlled trial. Ann Surg 2011;254(1):28-38. DOI: 10.1097/SLA.0b013e318221f0cf.

38. Alexander DJ, Ngoi SS, et al. Randomized trial of periportal peritoneal bupivacaine for pain relief after laparoscopic cholecystectomy. $\mathrm{Br} J$ Surg 1996;83:1223-1225.

39. Coughlin SM, Karanicolas PJ, et al. Better late than never? Impact of local analgesia timing on postoperative pain in laparoscopic surgery: a systematic review and metaanalysis. Surg Endosc 2010;24(12): 3167-3176. DOI: 10.1007/s00464-010-1111-1. Epub.

40. Larson GM. Ventral hernia repair by the laparoscopic approach. Surg Clin North Am 2009;80:1329-1340. DOI: 10.1016/s0039-6109(05)70228-0.

41. Ramshaw BJ, Esartia P, et al. Comparison of laparoscopic and open ventral herniorrhaphy. Am Surg 2009;65:827-831.

42. White P. The changing role of non-opioid analgesic techniques in the management of postoperative pain. Anesth Analg 2005;101:5-22. DOI: 10.1213/01.ane.0000177099.28914.a7. 